\title{
Oxidative Desulfurization of Gasoline by Ionic Liquids Coupled with Extraction by Organic Solvents
}

\author{
Rashid Abro, ${ }^{a}$ Shurong Gao, ${ }^{a}$ Xiaochun Chen, ${ }^{* a}$ Guangren Yu, ${ }^{* a}$ Ahmed A. Abdeltawab ${ }^{b}$ \\ and Salem S. Al-Deyab ${ }^{b}$ \\ ${ }^{a}$ Beijing Key Laboratory of Membrane Science and Technology \& College of Chemical Engineering, \\ Beijing University of Chemical Technology, 100029 Beijing, P. R. China \\ ${ }^{b}$ Department of Chemistry, College of Science, King Saud University, 11451 Riyadh, \\ Saudi Arabia
}

\begin{abstract}
In this work, desulfurization of real fluidized catalytic cracking (FCC) gasoline was investigated in dual steps; first in oxidative desulfurization (ODS) using imidazolium and pyrrolidonium based Brønsted acidic ionic liquids (ILs) as solvent and catalyst and hydrogen peroxide as oxidant. In second step, extractive desulfurization took place using organic solvents of furfural, furfural alcohol and ethylene glycol. Variety of factors such as temperature, time, mass ratio of oil/ILs and regeneration and recycling of ILs, multiple-step desulfurization of ILs and organic solvents and solvent/oil ratio were also investigated. The S-content was significantly decreased to ca. $18 \mathrm{ppm}$ from initial S-content of $260 \mathrm{ppm}$ with a total S-removal of ca. $95 \%$ in one-step ODS using pyrrolidonium based ILs coupled with five-step extraction desulfurization (EDS) using furfural alcohol as extractant. This work shows that oxidative desulfurization using ionic liquids coupled with extractive desulfurization using organic solvents is a potential method to produce clean gasoline.
\end{abstract}

Keywords: gasoline, oxidative desulfurization, extractive desulfurization, ionic liquids, ultra-clean fuel oil

\section{Introduction}

The emission of sulfur (S) during combustion from light fuel oils, coupled with increasing automobiles has heightened concern on environmental pollution. The sustained emission of these gases leads to air pollution, acid rain, and global climate change as well as increases health risk from continuous exposure to this smog. Economically, it affects the catalytic converter emission of vehicles resulting in inefficient fuel utilization and poor performance. In 1998, the European Union instituted legislations to monitor the S-limits in fuel oils by setting up mandatory S-content limit to be less than $10 \mathrm{ppm}$ or negligible level. ${ }^{1-3}$ In March 2014, the United States Environmental Protection Agency proposed new standards to further reduce the $\mathrm{S}$-content from the current 30 to $10 \mathrm{ppm}$. In recent years, Japan has also made significant efforts to reduce the $\mathrm{S}$-content from 500 to $50 \mathrm{ppm}$. Some European countries including Denmark and Germany

*e-mail: gryu@mail.buct.edu.cn, chenxc@mail.buct.edu.cn have imposed taxes on fuel oil refineries that fail to meet the standard (Figure 1 shows the maximum gasoline S-limits in different regions). ${ }^{4}$ The goal, of course, is to realize ultra-low, possibly zero, S-content in gasoline in the not-too-distant future.

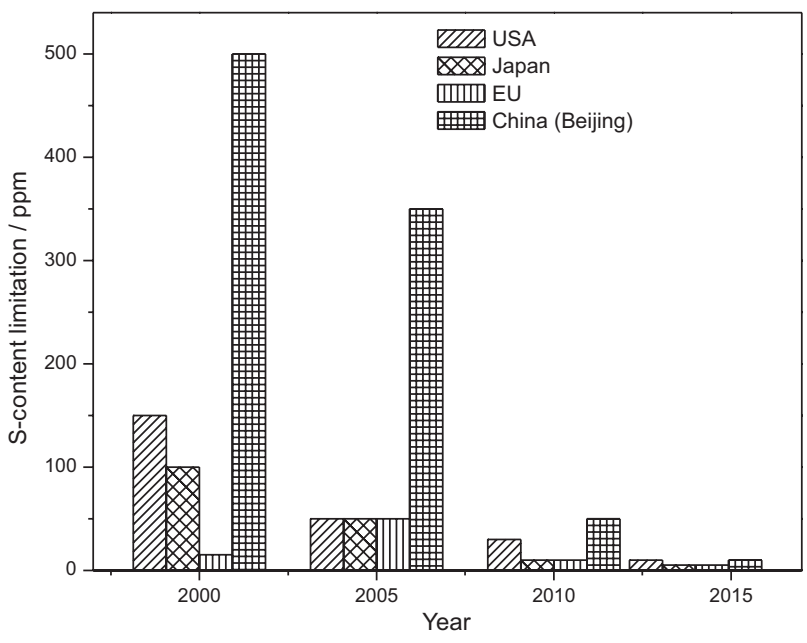

Figure 1. Proposed sulfur limitations in gasoline in different countries. ${ }^{3,5}$ 
Hydrodesulfurization (HDS) is the well-established method employed in industry for this regard, where S-compounds are converted into hydrogen sulfide $\left(\mathrm{H}_{2} \mathrm{~S}\right)$ in the presence of catalyst at elevated temperatures and pressures. HDS has some disadvantages such as the need for expensive catalysts, high temperature (300 to $340{ }^{\circ} \mathrm{C}$ ) and high pressure (20 to $100 \mathrm{~atm}$ of $\mathrm{H}_{2}$ ). More importantly, aliphatic thiols and sulfides can effectively be removed in HDS while thiophene and its derivatives are not easily removed because of the steric hindrance for catalysis. ${ }^{6}$ Therefore, some alternative techniques such as adsorption desulfurization (ADS), ${ }^{7-9}$ extraction desulfurization (EDS), ${ }^{10-12}$ oxidation desulfurization (ODS), ${ }^{13,14}$ and biodesulfurization (BDS) $)^{15,16}$ are sought in order to complement the HDS process. ODS is more competitive and efficient in removing the thiophenic S-compounds under mild conditions with low costs. ${ }^{17-19}$ The use of molecular organic solvents such as dimethylsulfoxide (DMSO), dimethylformamide (DMF) and acetonitrile in ODS has been patented; some problems, however, exist in employing these organic solvents such as loss, contamination, regeneration, recycling and safety issues stemming from the volatile nature of organic solvents. ${ }^{20-25}$

Recently, ionic liquids (ILs) have attracted increasing attention thanks to their desirable physicochemical properties such as negligible volatility, easy alteration of cation/anion structure for specific applications, high thermochemical stability and remarkable ability in dissolving organic/ inorganic compounds. With wide-ranging applications in separation technology, nanotechnology, catalysis, electrochemistry, etc., ILs are being acclaimed as "green" and "designer" solvents. ${ }^{26-28}$ Several ILs have been studied as solvent in EDS for S-removal from fuel oils such as [1-butyl3-methylimidazolium (Bmim) $] \mathrm{PF}_{6},{ }^{29,30}[\mathrm{Bmim}] \mathrm{BF}_{4}{ }^{29,30}$ [1-methyl-3-octylimidazolium (Omim) $] \mathrm{BF}_{4},{ }^{31,32}$ $[\mathrm{Bmim}]\left[\mathrm{CF}_{3} \mathrm{SO}_{3}\right],{ }^{33}[\mathrm{Omim}]\left[\mathrm{OcSO}_{4}\right],{ }^{33}[\mathrm{Bmim}] \mathrm{AlCl}_{4},{ }^{34}$ [Bmim] $\mathrm{Cl} / \mathrm{Cu}_{2} \mathrm{Cl}_{3},{ }^{35}$ [1-ethyl-3-methylimidazolium (Emim)] dicyanamide (DCA) ${ }^{36}$ and [Bmim]DCA. ${ }^{37}$ Compared with EDS alone using ILs, some researchers observed that ODS is much more efficient and S-removal can be increased up to $90 \%$ from $10-40 \%$ in EDS, such as [butyl6-methylquinolinium (Bmimquin)]DCA in ODS process removed $99.9 \%$ of S-contents at mild conditions from model diesel fuel. ${ }^{38}$ In a typical ODS, S-compounds in gasoline fuel are extracted into the IL phase first, then oxidized by some oxidant, and the oxidized product is more polar and easily removable. The oxidant is usually the cheap and environmentally benign hydrogen peroxide $\left(\mathrm{H}_{2} \mathrm{O}_{2}\right)$ solution, while the catalysts are usually acetic acid, ${ }^{39}$ vanadium pentoxide, ${ }^{40}$ decatungstates,${ }^{41}$ peroxotungsten, or peroxomolybdenum complexes. ${ }^{42}$

Due to regeneration and contamination problems of acid catalyst, recently, some acidic ILs have been used in ODS, where those ILs act as both catalyst and solvent, and no other acid catalyst is added, as shown in Figure 2. In the literature, most emphases are placed on model fuel oils, which are configured by S-compounds (thiophene, dibenzothiphene, and their derivatives) and a certain amount of aliphatic (hexane, heptane, $n$-dodecane, etc.) and aromatic (usually toluene) compounds while the investigations on real feedstock are rather scarce, as listed in Table 1. The results for model oils may not present a conclusive argument.

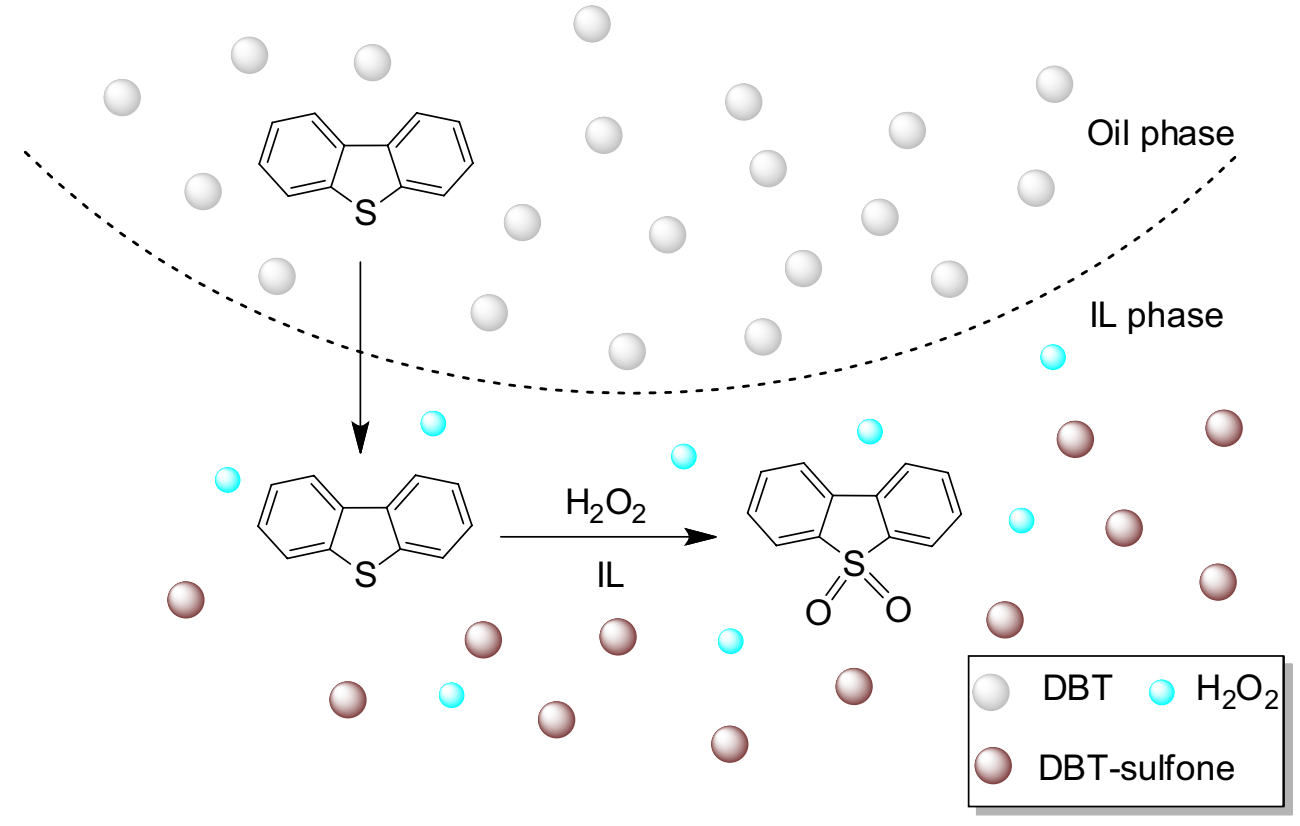

Figure 2. Oxidation of S-component using $\mathrm{H}_{2} \mathrm{O}_{2}$ and ILs. 
Table 1. ODS of real fuels by ILs

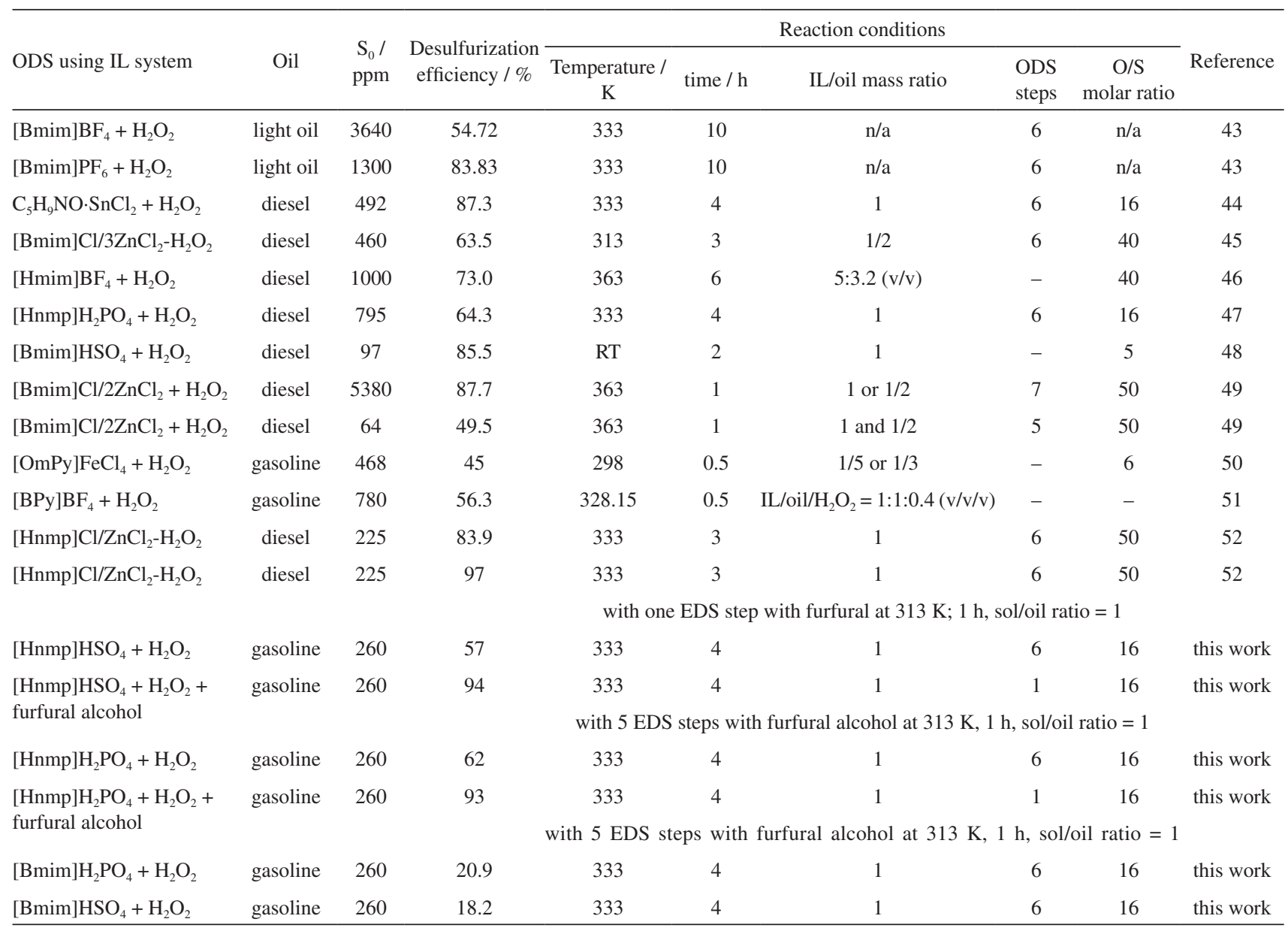

ODS: oxidative desulfurization; IL: ionic liquid; $\mathrm{S}_{0}$ : initial S-content; Bmim: 1-butyl-3-methylimidazolium; n/a: not applicable; Hmim: 1-hexyl-3methylimidazolium; Hnmp: $N$-methyl pyrrolidonium; RT: room temperature; OmPy: 1-octyl-3-methylpyridinium; BPy: $N$-butylpyridinium.

In this work, we synthesized four Brønsted acidic ILs namely $[\mathrm{Hnmp}] \mathrm{HSO}_{4},[\mathrm{Hnmp}] \mathrm{H}_{2} \mathrm{PO}_{4},[\mathrm{Bmim}] \mathrm{H}_{2} \mathrm{PO}_{4}$ and $[\mathrm{Bmim}] \mathrm{HSO}_{4}$ and investigated the desulfurization of real fluidized catalytic cracking (FCC) gasoline in two steps: the first in ODS using above ILs as extractant and catalyst and $\mathrm{H}_{2} \mathrm{O}_{2}$ as oxidant; the second in EDS using different organic solvents of furfural, furfural alcohol and ethylene glycol (the ILs, also organic solvents, used in this work are illustrated in Figure 3), involving a variety of factors such as temperature, time, and regeneration of ILs, multiple-step desulfurization and solvent/oil mass ratio. These ILs act as both catalyst and solvent, also can easily be prepared with cheaper starting materials and can be regenerated easily, whereas all selected organic solvents are also reasonable candidates for EDS due to their physical characteristics, i.e., immiscible with gasoline (gasoline is miscible with most organic solvents), low volatility, less operational problems, good thermal stability and high boiling points $\left(160-200{ }^{\circ} \mathrm{C}\right)$. This work shows that ODS using ILs coupled with EDS using organic solvents is a potential method to produce clean gasoline.

\section{Experimental}

\section{Chemicals and material}

The chemicals are: $N$-methylimidazole $(\geq 99.0 \%)$ (Shanghai SenHao Fine Chemical); ethyl acetate $(\geq 99.0 \%)$, $\mathrm{H}_{2} \mathrm{O}_{2}$ aqueous solution (30 wt.\%), $\mathrm{H}_{2} \mathrm{SO}_{4}(98 \%), \mathrm{H}_{2} \mathrm{PO}_{4}$ (85\%), $\mathrm{N}$-methylpyrrolidone (NMP), furfural alcohol, furfural and ethylene glycol (Beijing Chemical Plant). $\mathrm{N}$-Methylimidazole is further purified by distillation, and the other chemicals were used as received without further purification. Real FFC gasoline fuel with a total S-content of 260 ppm was supplied by SINOPEC Beijing Yanshan Petrochemical Co., Ltd (properties of gasoline are given in Table 2). 


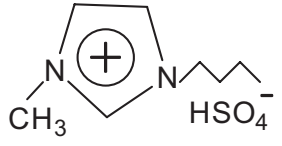

$[\mathrm{Bmim}] \mathrm{HSO}_{4}$

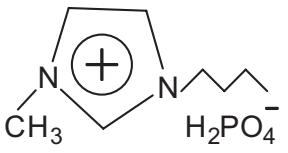

$[\mathrm{Bmim}] \mathrm{H}_{2} \mathrm{PO}_{4}$<smiles>O=Cc1ccco1</smiles>

Furfural

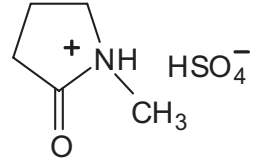

$[\mathrm{Hnmp}] \mathrm{HSO}_{4}$

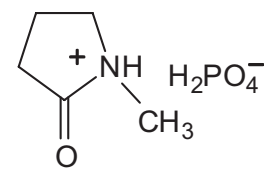

$[\mathrm{Hnmp}] \mathrm{H}_{2} \mathrm{PO}_{4}$

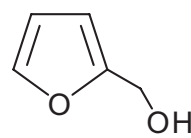

Furfural alcohol<smiles>OCCO</smiles>

Ethylene glycol

Figure 3. Structures of ILs and organic solvents used in this work.

Table 2. Physicochemical properties of gasoline

\begin{tabular}{lc}
\hline Property & Value \\
\hline S-content & $260 \mathrm{ppm}$ \\
Viscosity $\left(20^{\circ} \mathrm{C}\right)$ & $0.701 \mathrm{~mm}^{2} \mathrm{~s}^{-1}$ \\
Boiling point & initially $40{ }^{\circ} \mathrm{C}$ \\
Density & $0.7-0.8 \mathrm{~g} \mathrm{~cm}^{-3}$ \\
Color & pale brown \\
Vapor pressure & ca. $600 \mathrm{~mm} \mathrm{Hg}$ \\
Flash point & $-46^{\circ} \mathrm{C}$ \\
\hline
\end{tabular}

Synthesis of ILs

$[\mathrm{Hnmp}] \mathrm{HSO}_{4},[\mathrm{Hnmp}] \mathrm{H}_{2} \mathrm{PO}_{4},[\mathrm{Bmim}] \mathrm{HSO}_{4}$ and [Bmim] $\mathrm{H}_{2} \mathrm{PO}_{4}$ were synthesized according to the procedures as mentioned in the literature. ${ }^{53-55}$

\section{Preparation of $[\mathrm{Hnmp}] \mathrm{HSO}_{4}$ and $[\mathrm{Hnmp}] \mathrm{H}_{2} \mathrm{PO}_{4}$}

NMP $(60 \mathrm{~mL})$ was placed in a three-necked flask, which was provided with a stirrer at room temperature. Then, stoichiometric amount of $\mathrm{H}_{2} \mathrm{SO}_{4}(98 \%)$ or $\mathrm{H}_{2} \mathrm{PO}_{4}(85 \%)$ was added to the three-necked flask slowly over a period of $1 \mathrm{~h}$ while stirring at room temperature. The reaction mixture was stirred and heated to $80^{\circ} \mathrm{C}$ for $2 \mathrm{~h}$. The residual reactant and water were removed by a rotary evaporator. The IL was dried in vacuum to give the product as a colorless liquid.

The nature of cation and anion in $[\mathrm{Hnmp}] \mathrm{HSO}_{4}$ and $[\mathrm{Hnmp}] \mathrm{H}_{2} \mathrm{PO}_{4}$ was determined with Fourier transform infrared (FTIR) spectroscopy and nuclear magnetic resonance (NMR) spectra.

$[\mathrm{Hnmp}] \mathrm{HSO}_{4}$

IR $(\mathrm{KBr}) v_{\max } / \mathrm{cm}^{-1} 3406.2,2979.5,2895.7,2521.7$, 1825.8, 1698.4, 1495.5, 1460.9, 1409.8, 1313.0, 1230.4, 1167.7, 1021.7, 982.6, 881.0, 645.5, 578.4, 465, 434.8; ${ }^{1} \mathrm{H}$ NMR (400 MHz, $\left.\mathrm{D}_{2} \mathrm{O}\right) \delta 4.88(\mathrm{bs}, 1 \mathrm{H}), 3.24-3.20(\mathrm{t}$, $2 \mathrm{H}), 2.54$ (s, 3H), 2.17-2.13 (d, 1H).1.77-1.73 (m, 2H).

\section{$[\mathrm{Hnmp}] \mathrm{H}_{2} \mathrm{PO}_{4}$}

IR (KBr) $v_{\max } / \mathrm{cm}^{-1} 2940.0,2891.3,1627.7,1509.0$, 1408.8, 1307.6, 1260.9, 1117.0, 1003.7, 884.1, 747.8, 665.1, 665.1, 617.7, 486.2, 403; ${ }^{1} \mathrm{H}$ NMR (400 MHz, $\left.\mathrm{D}_{2} \mathrm{O}\right)$ $\delta 4.82$ (bs, $1 \mathrm{H}), 3.32-3.28$ (t, $2 \mathrm{H}), 2.45$ (s, 3H), 2.08-2.04 $(\mathrm{d}, 1 \mathrm{H}), 1.7-1.67(\mathrm{~m}, 2 \mathrm{H})$.

Preparation of $[\mathrm{Bmim}] \mathrm{HSO}_{4}$ and $[\mathrm{Bmim}] \mathrm{H}_{2} \mathrm{PO}_{4}$

$[\mathrm{Bmim}] \mathrm{HSO}_{4}$ and $[\mathrm{Bmim}] \mathrm{H}_{2} \mathrm{PO}_{4}$ derived from imidazole chloride salts were obtained by a drop-wise addition of one equivalent of concentrated $\mathrm{H}_{2} \mathrm{SO}_{4}$ (98\%) or $\mathrm{H}_{2} \mathrm{PO}_{4}(85 \%)$ to solution of the corresponding 1-butyl-3-methylimidazolium chloride in anhydrous methylene chloride. The reaction proceeded at room temperature for $24 \mathrm{~h}$ with vigorous stirring under a stream of dry nitrogen. Then, the mixture was dried in vacuum by a rotary evaporator to remove the $\mathrm{HCl}$ and solvent to obtain the viscous clear $[\mathrm{Bmim}] \mathrm{HSO}_{4}$ and $[\mathrm{Bmim}] \mathrm{H}_{2} \mathrm{PO}_{4}$.

\section{Desulfurization and recycling}

IL and desired amount of $30 \mathrm{wt} . \% \mathrm{H}_{2} \mathrm{O}_{2}$ were introduced into a $150 \mathrm{~mL}$ round-bottom flask. The FCC gasoline fuel was added, then mixture was magnetically stirred for specified time and temperature for ODS process. Then the mixture was allowed to settle for $5 \mathrm{~min}$ to obtain phase splitting and the S-content in the upper oil phase was measured. For EDS using organic solvents, desired amount of organic solvent and FCC gasoline fuel were put into $150 \mathrm{~mL}$ round-bottom flask. Then mixture was magnetically stirred at a desired time and temperature. The upper oil phase was periodically removed and analyzed for S-content. After each ODS, the bottom IL phase was treated with a rotary evaporator to remove impurities, and the IL was recycled.

\section{S-content analysis}

The S-content in real FFC gasoline fuel oil was analyzed by a WK-2D microcoulomb analyzer (Jiangfen 
Electroanalysis Co., Ltd.), in which high purity nitrogen gas was used as carrier gas while oxygen gas was used as reaction gas; select vaporization zone temperature: $620^{\circ} \mathrm{C}$; combustion zone temperature: $820{ }^{\circ} \mathrm{C}$; temperature of stable segment: $720^{\circ} \mathrm{C}$.

\section{Results and Discussion}

\section{ODS using ILs}

The ODS results of FFC gasoline fuel by four Brønsted ILs for one step at $60{ }^{\circ} \mathrm{C}$, time $=4 \mathrm{~h}$, IL/oil mass ratio $=1$ and $\mathrm{O} / \mathrm{S}$ molar ratio $=16$ are shown in Figure 4. Efficiency of S-removal from FFC gasoline follows the order $[\mathrm{Hnmp}] \mathrm{HSO}_{4}>[\mathrm{Hnmp}] \mathrm{H}_{2} \mathrm{PO}_{4}>[\mathrm{Bmim}] \mathrm{HSO}_{4}>$ $[\mathrm{Bmim}] \mathrm{H}_{2} \mathrm{PO}_{4}$ with $\mathrm{S}$-removal efficiencies of $25.3>$ $23.8>20.9>18.2 \%$, respectively. Here, the S-removal efficiency is defined as

S-removal efficiency $=\frac{\left(\mathrm{S}_{0}-\mathrm{S}_{\mathrm{f}}\right)}{\mathrm{S}_{0}} \times 100 \%$

where $\mathrm{S}_{0}$ is the S-content in the gasoline before ODS and $\mathrm{S}_{\mathrm{f}}$ is the $\mathrm{S}$-content after ODS. The acidities of $[\mathrm{Hnmp}] \mathrm{HSO}_{4}$ and $[\mathrm{Hnmp}] \mathrm{H}_{2} \mathrm{PO}_{4}$ are expected to be stronger than that of $[\mathrm{Bmim}] \mathrm{HSO}_{4}$ and $[\mathrm{Bmim}] \mathrm{H}_{2} \mathrm{PO}_{4}$, respectively, because there is acidic proton on $[\mathrm{Hnmp}]^{+}$, which is favorable when ILs act as acidic catalyst. [Hnmp $] \mathrm{HSO}_{4}$ and [Hnmp $] \mathrm{H}_{2} \mathrm{PO}_{4}$ with highest desulfurization efficiency are chosen to undergo further investigation for the different parameters on S-removal efficiency such as reaction time, temperature, multiple ODS steps, recycling efficiency.

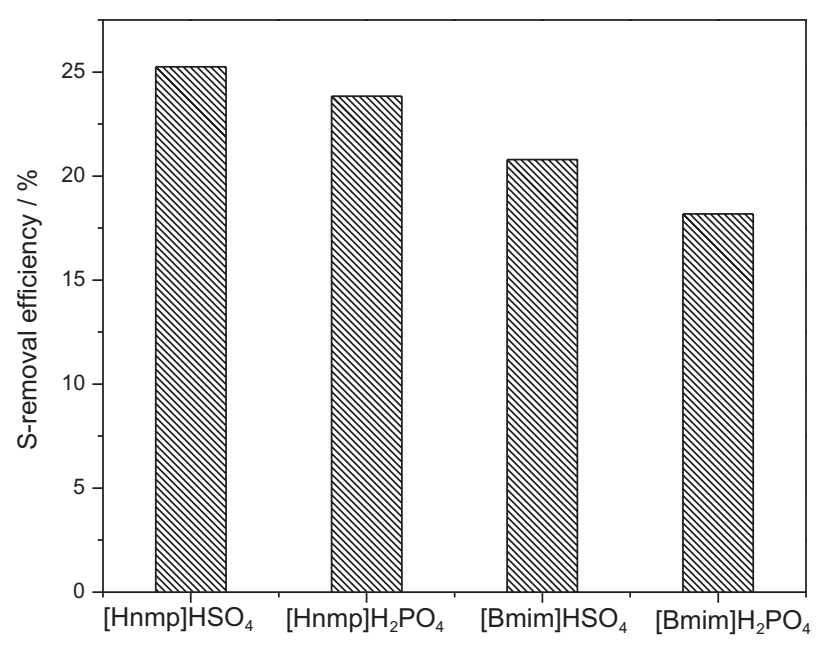

Figure 4. ODS S-removal efficiency by four Brønsted acidic ILs: $[\mathrm{Hnmp}] \mathrm{HSO}_{4},[\mathrm{Hnmp}] \mathrm{H}_{2} \mathrm{PO}_{4},[\mathrm{Bmim}] \mathrm{HSO}_{4}$, and $[\mathrm{Bmim}] \mathrm{H}_{2} \mathrm{PO}_{4}$ (after one-step ODS, $60^{\circ} \mathrm{C}, 4 \mathrm{~h}, 260 \mathrm{ppm}$ of initial S-content, 16 of molar ratio of $\mathrm{O} / \mathrm{S}, 1: 1$ of mass ratio of IL/oil).

\section{Reaction time}

The ODS results using [Hnmp] $\mathrm{HSO}_{4}$ and $[\mathrm{Hnmp}] \mathrm{H}_{2} \mathrm{PO}_{4}$ at 2, 4, and $6 \mathrm{~h}$ are shown in Figure 5. Four hours are enough to reach the equilibrium of desulfurization when the S-removal efficiencies are 25.4 and $23.7 \%$ for [ $\mathrm{Hnmp}] \mathrm{HSO}_{4}$ and $[\mathrm{Hnmp}] \mathrm{H}_{2} \mathrm{PO}_{4}$, respectively, at $60{ }^{\circ} \mathrm{C}$, IL/oil $=1$ and $\mathrm{O} / \mathrm{S}=16$ after single step, while S-removal are only slightly increased to 25.6 and $24.1 \%$, respectively, after 6 h. Two hours are too short when the S-removal efficiencies are 16.2 and $17.1 \%$ for $[\mathrm{Hnmp}] \mathrm{HSO}_{4}$ and $[\mathrm{Hnmp}] \mathrm{H}_{2} \mathrm{PO}_{4}$, respectively. Thus, $4 \mathrm{~h}$ may be considered as a moderate time for better ODS desulfurization result.

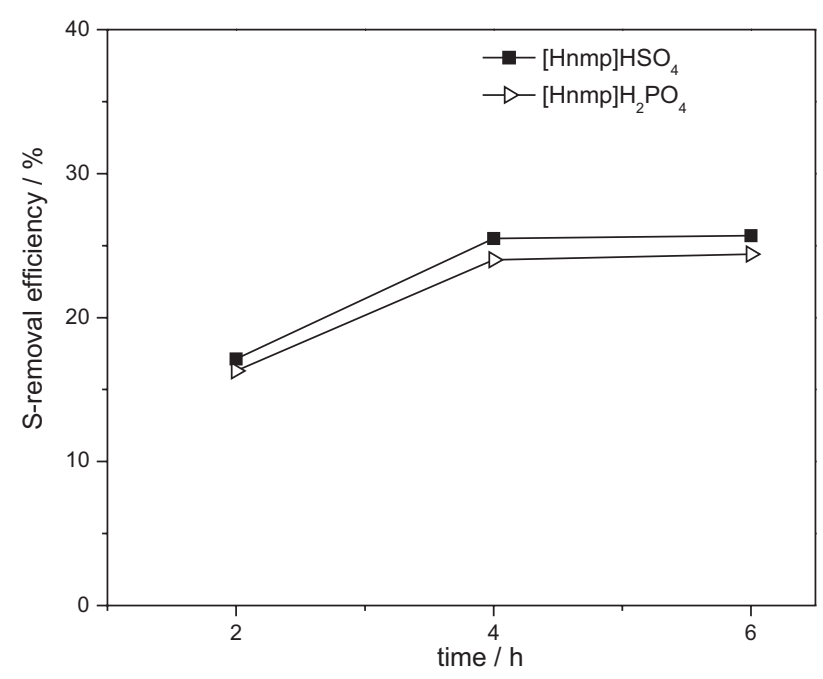

Figure 5. Influence of time on ODS S-removal efficiency of $[\mathrm{Hnmp}] \mathrm{H}_{2} \mathrm{PO}_{4}$ and $[\mathrm{Hnmp}] \mathrm{HSO}_{4}$ (after one-step ODS, $60{ }^{\circ} \mathrm{C}, 260 \mathrm{ppm}$ of initial S-content, 16 of molar ratio of $\mathrm{O} / \mathrm{S}, 1: 1$ of mass ratio of IL/oil).

\section{Reaction temperature}

The effects of temperature on ODS desulfurization performance by $[\mathrm{Hnmp}] \mathrm{HSO}_{4}$ and $[\mathrm{Hnmp}] \mathrm{H}_{2} \mathrm{PO}_{4}$ are investigated at 30,45 and $60{ }^{\circ} \mathrm{C}$. The results are shown in Figure 6. A rise in the reaction temperature from 30 to $60{ }^{\circ} \mathrm{C}$ leads to a remarkable increase in the S-removal efficiency using [Hnmp] $\mathrm{HSO}_{4}$ and $[\mathrm{Hnmp}] \mathrm{H}_{2} \mathrm{PO}_{4}$ from 12 to $25.3 \%$ and 11.6 to $23.7 \%$, respectively, with one step ( $4 \mathrm{~h}, \mathrm{IL} / \mathrm{oil}=1, \mathrm{O} / \mathrm{S}=16$ ). These results can be explained by the strong dependence of the oxidation reaction rate on the reaction temperature. In addition, higher temperature may decrease the viscosity of ILs, enhance effective mixing and inter-phase mass transfer, and $\mathrm{H}_{2} \mathrm{O}_{2}$ may be used effectively after decomposition. ${ }^{50-52}$ On the other hand, too high temperatures are not good choice and might lead to auxiliary risk of explosion in the process, although high temperature enhances $\mathrm{H}_{2} \mathrm{O}_{2}$ decomposition. Therefore, reaction at higher temperature should be carefully avoided. 
Thus, a moderate temperature of $60{ }^{\circ} \mathrm{C}$ presents the best desulfurization result.

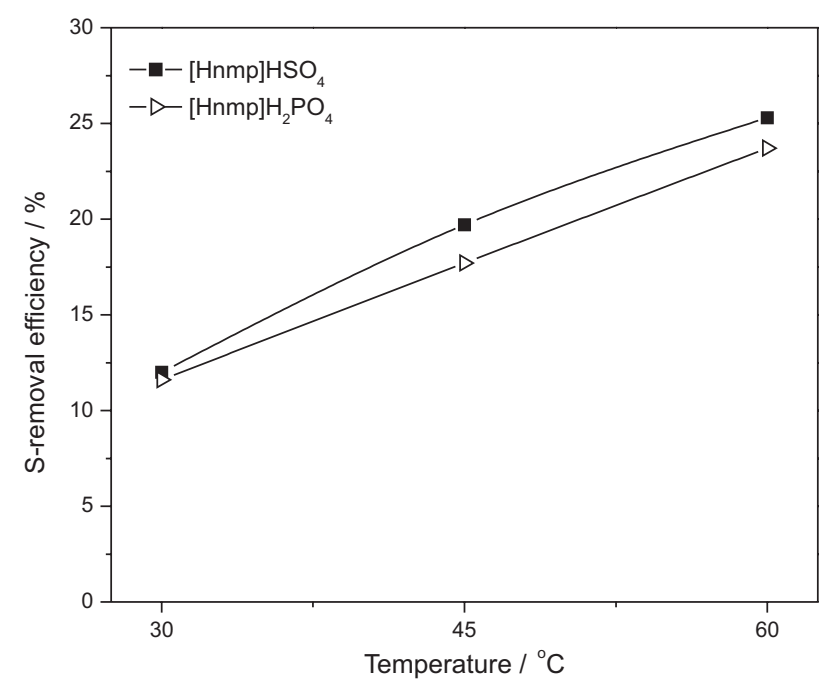

Figure 6. Influence of temperature for ODS S-removal efficiency of $[\mathrm{Hnmp}] \mathrm{H}_{2} \mathrm{PO}_{4}$ and $[\mathrm{Hnmp}] \mathrm{HSO}_{4}$ (after one-step ODS, $4 \mathrm{~h}, 260 \mathrm{ppm}$ of initial S-content, 16 of molar ratio of $\mathrm{O} / \mathrm{S}, 1: 1$ of mass ratio of IL/oil).

\section{IL regeneration}

Regeneration of ILs is a necessary process from environmental and economical point of view. After each ODS run, the ILs phase undergoes rotary evaporation to remove impurities, and then the system is charged again with fresh $\mathrm{H}_{2} \mathrm{O}_{2}$ solution for the next ODS cycle. The desulfurization results by $[\mathrm{Hnmp}] \mathrm{HSO}_{4}$ and $[\mathrm{Hnmp}] \mathrm{H}_{2} \mathrm{PO}_{4}$ after six cycles are shown in Figure 7. Results indicate that [Hnmp] $\mathrm{HSO}_{4}$ and $[\mathrm{Hnmp}] \mathrm{H}_{2} \mathrm{PO}_{4}$ can be regenerated and then recycled more than six times with no notable decline in efficiency, e.g., the S-removal only drops from 25.2 to $23.7 \%$ for [ $\mathrm{Hnmp}] \mathrm{HSO}_{4}$ and 23.8 to $22.4 \%$ for $[\mathrm{Hnmp}] \mathrm{H}_{2} \mathrm{PO}_{4}$. This small decline might be ascribed to accumulation of oxidation products. ${ }^{52}$

\section{Multiple-step ODS}

ODS by multiple-step is an effective way to reduce the S-content of heterocyclic compounds in FCC gasoline. The desulfurization results after multiple-step are shown in Figure 8. After first ODS step, S-content from real FCC gasoline decreased from 260 to $194.6 \mathrm{ppm}$ by [Hnmp] $\mathrm{HSO}_{4}$, and to $198 \mathrm{ppm}$ by [Hnmp] $\mathrm{H}_{2} \mathrm{PO}_{4}$ with 25.3 and $23.8 \%$ desulfurization efficiencies. After six ODS cycles, desulfurization efficiencies of real FFC gasoline fuel by [Hnmp] $\mathrm{HSO}_{4}$ and [Hnmp] $\mathrm{H}_{2} \mathrm{PO}_{4}$ increased to 57 and $62 \%$, respectively. Overall, this performance is not at desired level, when we compare these results with ODS using ILs of model fuels from literature due to complex composition of real FCC gasoline.
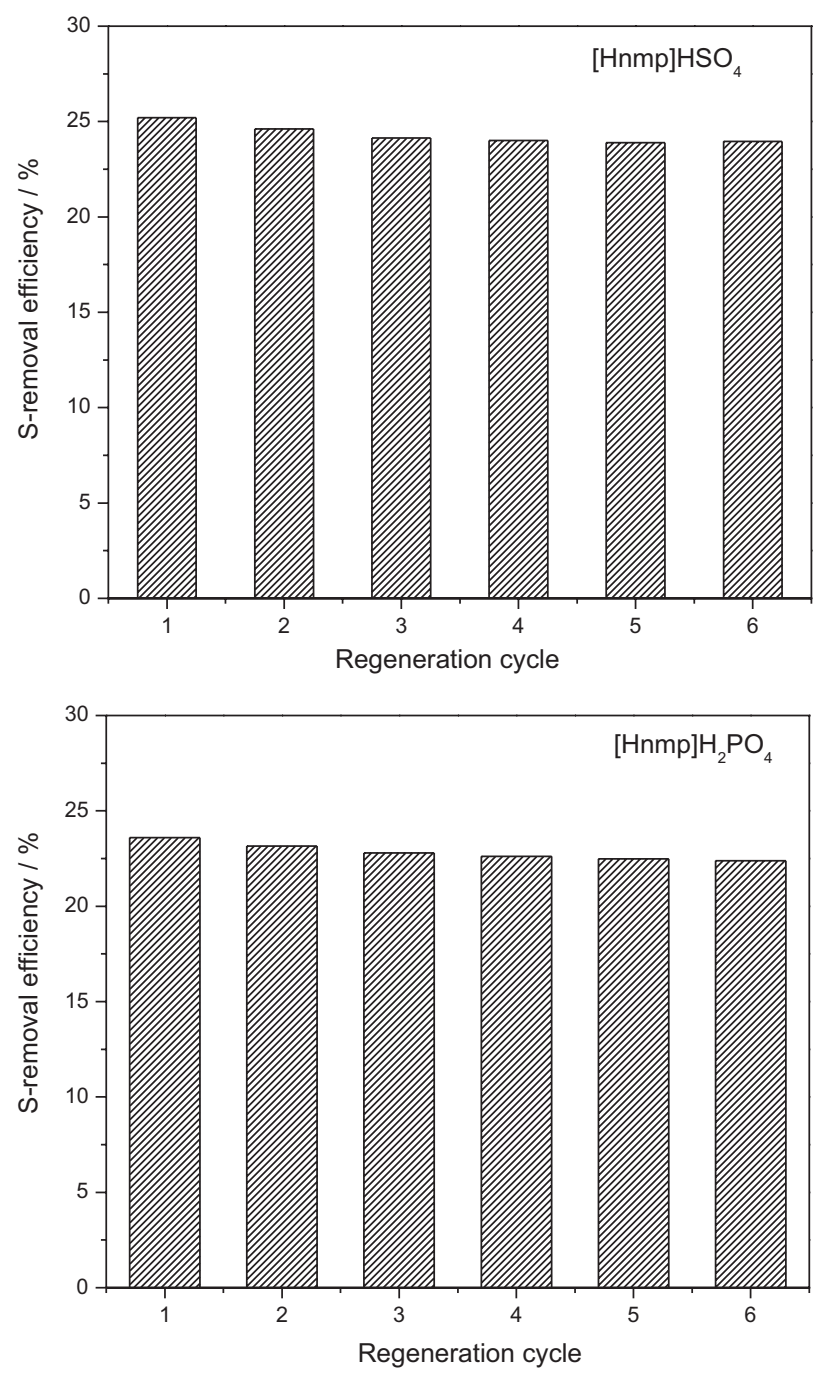

Figure 7. Influence of IL recycling on S-removal efficiency by [Hnmp] $\mathrm{HSO}_{4}$ and [Hnmp] $\mathrm{H}_{2} \mathrm{PO}_{4}$ (after one-step ODS, $60^{\circ} \mathrm{C}, 4 \mathrm{~h}, 260 \mathrm{ppm}$ of initial S-content, 16 of molar ratio of $\mathrm{O} / \mathrm{S}, 1: 1$ of mass ratio of IL/oil).

\section{EDS using organic solvent after ODS}

The EDS results by furfural, ethylene glycol and furfural alcohol for gasolines A and B are shown in Figure 9, where gasoline $\mathrm{A}$ is the gasoline after one-step ODS by $[\mathrm{Hnmp}] \mathrm{HSO}_{4}$ and gasoline $\mathrm{B}$ is that after one-step ODS by $[\mathrm{Hnmp}] \mathrm{H}_{2} \mathrm{PO}_{4}$. As shown in Figure 9, these solvents present very different EDS capability. It is observed interestingly that the final $\mathrm{S}$-contents in gasoline can be reduced to $<20 \mathrm{ppm}$ with about $95 \%$ S-removal after 5-step EDS by furfural and furfural alcohol; while the EDS capability by ethylene glycol is far from that by furfural and furfural alcohol, e.g., the final S-content in gasoline is larger than $110 \mathrm{ppm}$ with only about 55\% S-removal by ethylene glycol. As shown in Table 1, where some ODS results of real gasoline and diesel fuel using ILs are summarized, our results are very competitive. It has to be mentioned that the ODS results 

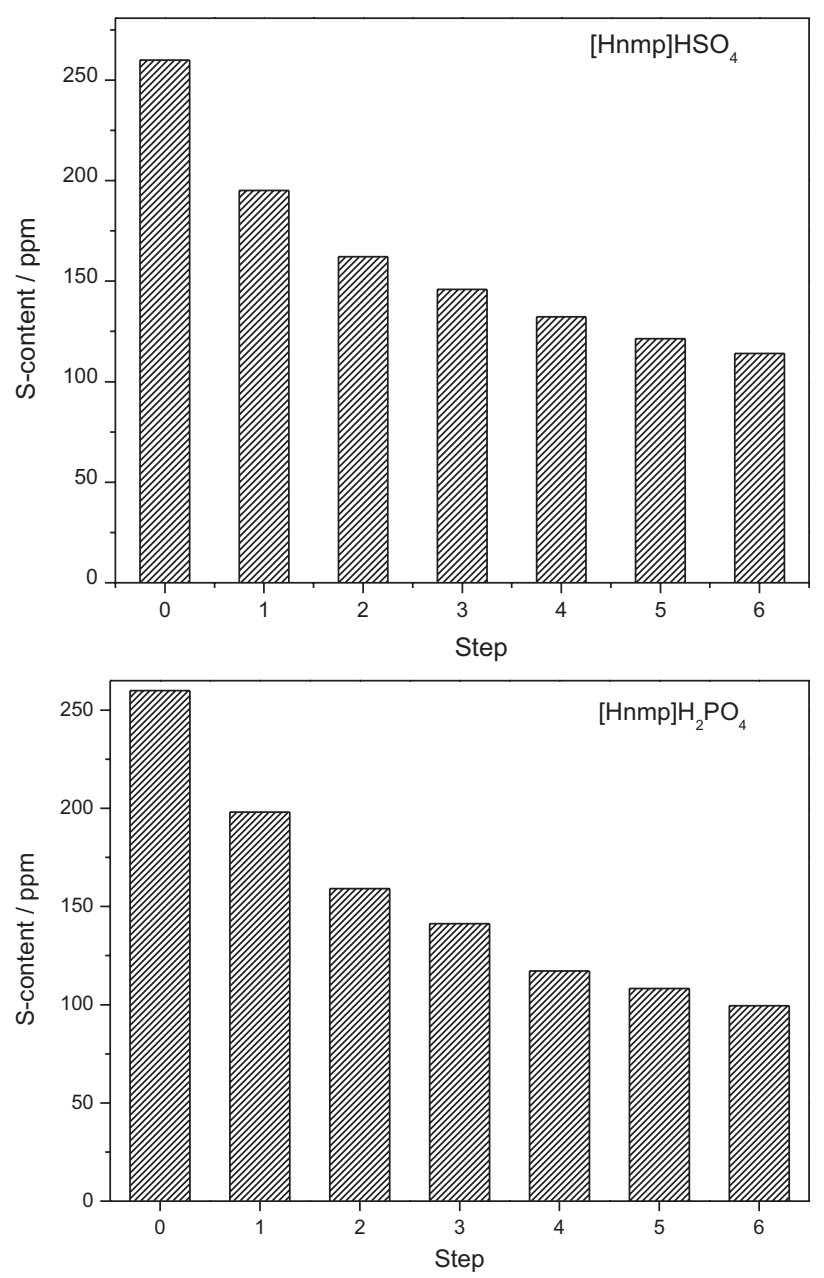

Figure 8. Influence of multiple steps of ODS desulfurization of $[\mathrm{Hnmp}] \mathrm{HSO}_{4}$ and $[\mathrm{Hnmp}] \mathrm{H}_{2} \mathrm{PO}_{4}\left(60^{\circ} \mathrm{C}, 4 \mathrm{~h}, 260 \mathrm{ppm}\right.$ of initial S-content, 16 of molar ratio of $\mathrm{O} / \mathrm{S}, 1: 1$ of mass ratio of IL/oil).

for gasoline are not as good as diesel fuel, which might be ascribed to the different $\mathrm{S}$-species in gasoline and diesel fuel. Further, Figure 9 shows furfural alcohol has slightly better ODS capacity than furfural, and furfural alcohol can reduce the S-content in gasoline A to $16.1 \mathrm{ppm}$ (93\% S-removal) and in gasoline B to $16.8 \mathrm{ppm}(94 \%$ S-removal). Furfural alcohol was chosen to undergo further investigation for the extraction temperature, extraction time, and solvent/gasoline ratio for gasolines A and B.

\section{Extraction temperature}

The results of one-step EDS by furfural alcohol for gasolines $\mathrm{A}$ and $\mathrm{B}$ at $30,40,50$ and $60{ }^{\circ} \mathrm{C}$ are shown in Figure 10. The best results are obtained at $40^{\circ} \mathrm{C}$, where the $\mathrm{S}$-contents are reduced to 144 and $142 \mathrm{ppm}$ for gasolines A and $\mathrm{B}$, respectively ( $1 \mathrm{~h}$, mass ratio of solvent/oil 1:1). The S-removals at $30{ }^{\circ} \mathrm{C}$ are slightly lower than that at $40{ }^{\circ} \mathrm{C}$, which might be ascribed to the slow mass transfer at lower
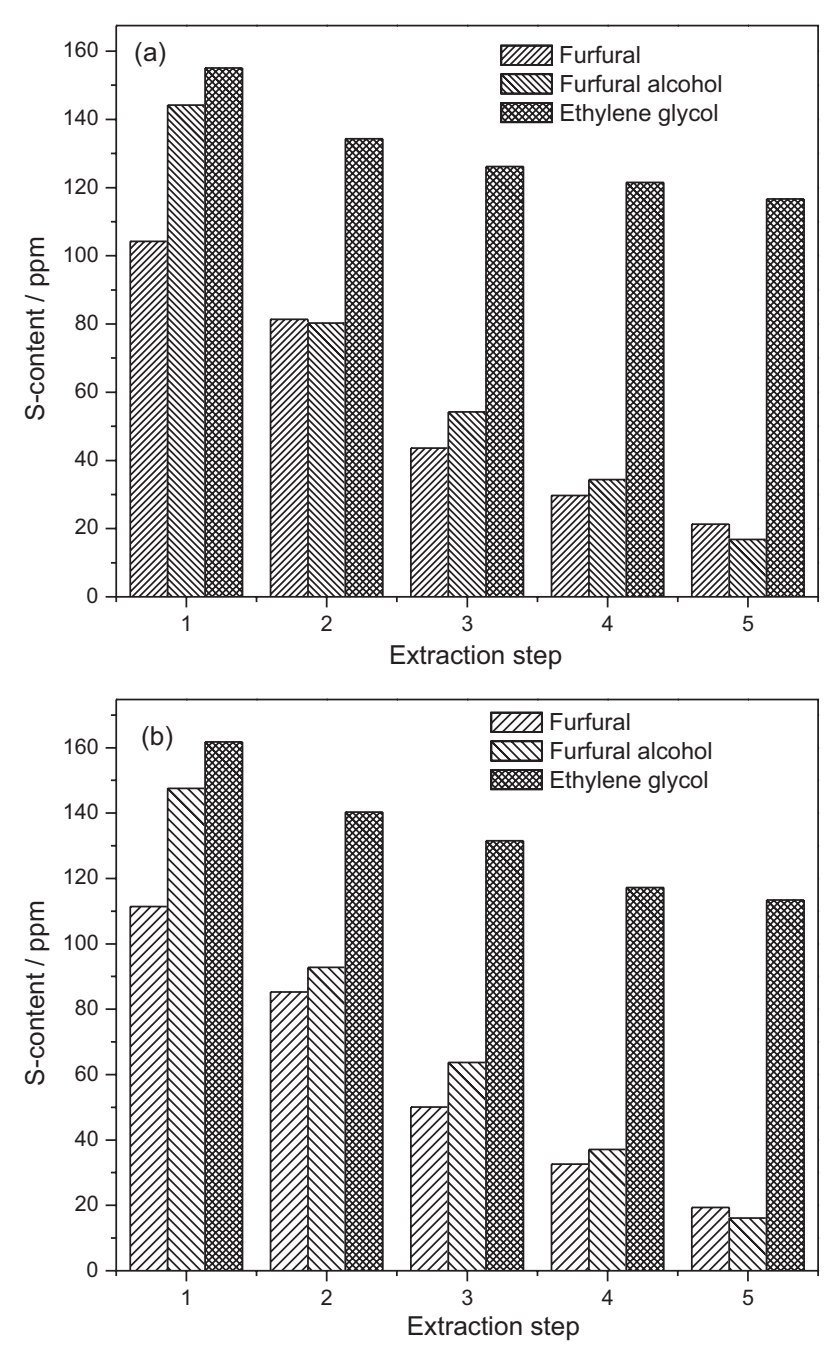

Figure 9. EDS S-removal efficiency of (a) gasoline A and (b) gasoline B by organic solvents $\left(40^{\circ} \mathrm{C}, 1 \mathrm{~h}, 1: 1\right.$ of mass ratio of solvent/oil).

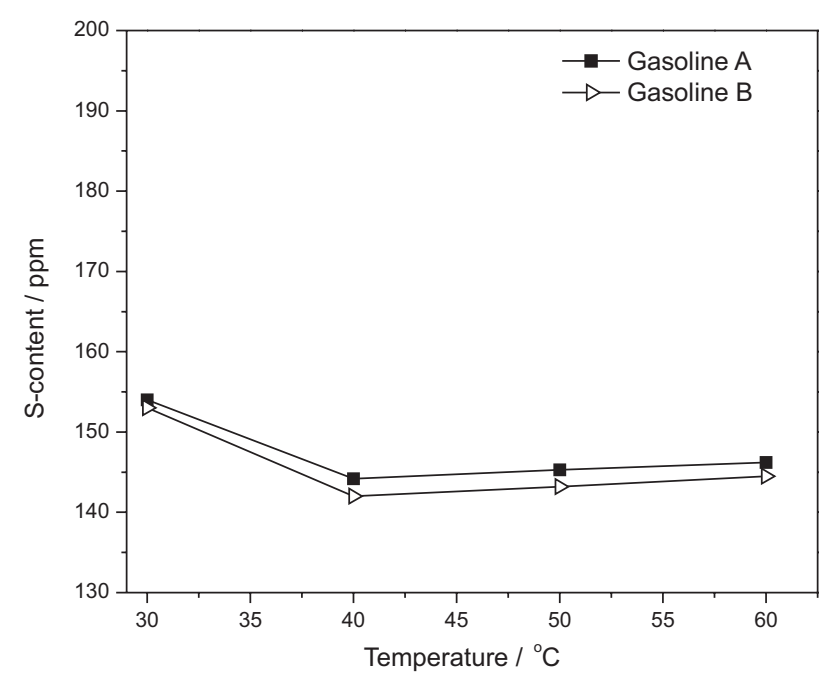

Figure 10. Influence of temperature for EDS S-removal efficiency for gasolines A and B (after one-step EDS, 1 h, 1:1 of mass ratio of solvent/oil). 
temperature. As a whole, the temperature has limited impact on desulfurization in the investigated temperature range.

\section{Extraction time}

The results of one-step EDS by furfural alcohol for gasolines A and B at 15, 30, 60 and 120 min are shown in Figure 11. As shown in Figure 11, the extractive equilibrium can be reached after $30 \mathrm{~min}$, when the S-contents are decreased to 143 and $145 \mathrm{ppm}$ for gasolines A and B, respectively.

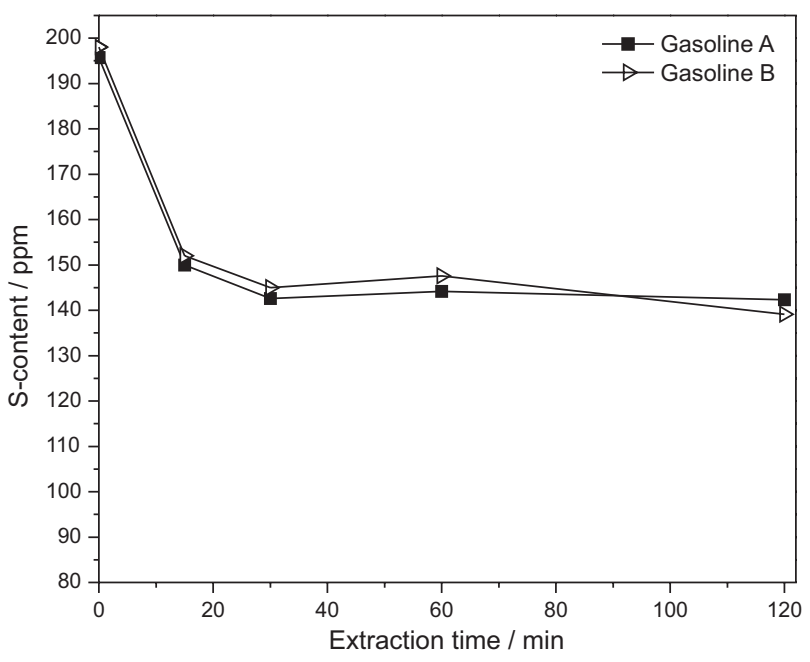

Figure 11. Influence of time for EDS S-removal efficiency for gasolines A and B (after one-step EDS, $40{ }^{\circ} \mathrm{C}, 1: 1$ of mass ratio of solvent/oil).

\section{Solvent/oil ratio}

The solvent/oil mass ratio is one of the important factors for the selectivity of solvent for desulfurization. The results of one-step EDS by furfural alcohol for gasolines A and $\mathrm{B}$ at the solvent/oil mass ratios of 3:1, 2:1, 1:1 and 1:2 are shown in Figure 12. As expected, more S-removal is observed with more furfural alcohol, i.e., a larger solvent/ oil mass ratio. We have to carefully select the solvent/oil mass ratio and compare between the S-removal efficiency and the solvent cost in industry.

\section{Conclusions}

ODS by ILs, as an alternative method to HDS, has been intensively studied recently. In this work, we synthesized four Brønsted acidic ILs of [Hnmp $] \mathrm{HSO}_{4}$, [Hnmp $] \mathrm{H}_{2} \mathrm{PO}_{4}$, $[\mathrm{Bmim}] \mathrm{H}_{2} \mathrm{PO}_{4}$ and $[\mathrm{Bmim}] \mathrm{HSO}_{4}$ that are easily prepared with cheap starting materials, and investigated the desulfurization of real FCC gasoline in two steps, first ODS using these ILs as solvent and catalyst with $30 \mathrm{wt} . \% \mathrm{H}_{2} \mathrm{O}_{2}$ as oxidant, and second EDS using different organic solvents of furfural,

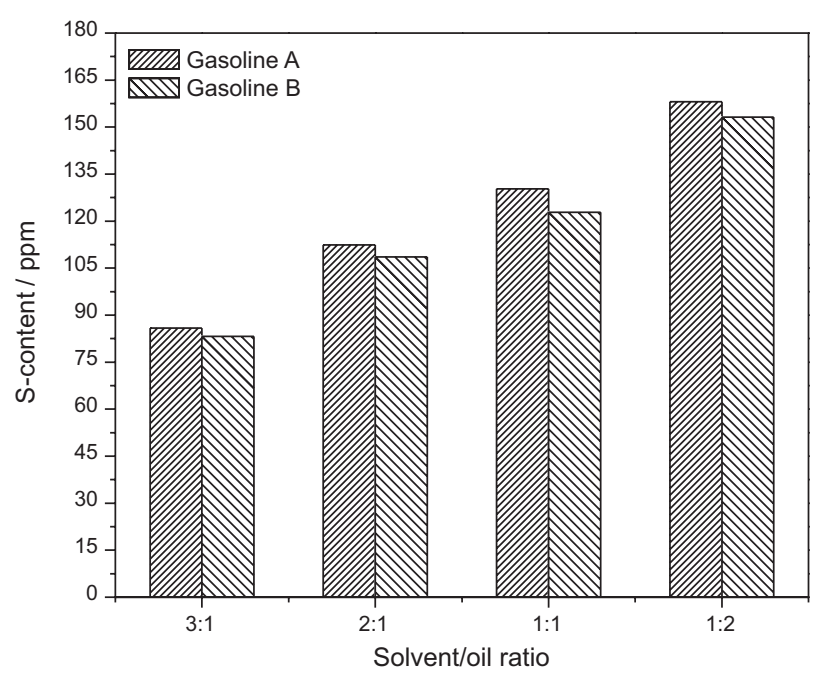

Figure 12. Influence of solvent/oil ratio for EDS S-removal efficiency for gasolines A and B (after one-step EDS, $40{ }^{\circ} \mathrm{C}, 1 \mathrm{~h}$ ).

furfural alcohol and ethylene glycol as extractants. The more acidic [Hnmp] ILs with proton have better ODS performance than [Bmim] ILs, following [Hnmp] $\mathrm{HSO}_{4}>[\mathrm{Hnmp}] \mathrm{H}_{2} \mathrm{PO}_{4}>$ $[\mathrm{Bmim}] \mathrm{HSO}_{4}>[\mathrm{Bmim}] \mathrm{HPO}_{4}$. The S-content in the FCC gasoline with initial S-content of $260 \mathrm{ppm}$ can be decreased to $194 \mathrm{ppm}\left(25.3 \% \mathrm{~S}\right.$-removal) by $[\mathrm{Hnmp}] \mathrm{HSO}_{4}$ and $198 \mathrm{ppm}$ (23.7\% S-removal) by [Hnmp] $\mathrm{H}_{2} \mathrm{PO}_{4}$ after one-step ODS $\left(60^{\circ} \mathrm{C}, \mathrm{IL} / \mathrm{oil}=1, \mathrm{O} / \mathrm{S}=16\right)$, and be further decreased to $111 \mathrm{ppm}$ (57\% S-removal) and $99 \mathrm{ppm}$ (62\% S-removal), respectively, after six-step ODS at the same conditions. The $\mathrm{S}$-content in gasoline after one-step ODS can be significantly decreased to $<20$ ppm by EDS using organic solvents, e.g., the five-step EDS using furfural alcohol as extractant $\left(40^{\circ} \mathrm{C}\right.$, $1 \mathrm{~h}$, mass ratio of solvent/oil 1:1) can reduce the S-content to 16-17 ppm with ca. $94 \%$ S-removal. The work shows that ODS using ILs coupled with EDS using organic solvents is a potential method to produce clean gasoline.

\section{Acknowledgments}

This work was financially supported by National Natural Science Foundation of China (21176021, 21276020). We extend our appreciation to the Deanship of Scientific Research at King Saud University for funding the work through the research group project No. RG-1436-026.

\section{References}

1. Abdalla, Z. E. A.; Li, B.; Tufail, A.; J. Ind. Eng. Chem. 2009 , 15,780 .

2. Seeberger, A.; Jess, A.; Green Chem. 2010, 12, 602.

3. Abro, R.; Abdeltawab, A. A.; Al-Deyab, S. S.; Yu, G.; Qazi, A. B.; Gao, S.; Chen, X.; RSC Adv. 2014, 67, 35302. 
4. Ibrahim, J. J.; Gao, S.; Abdeltawab, A. A.; Al-Deyab, S. S.; Yu,L.; Yu, G.; Chen, X.; Yong, X.; Sep. Sci. Technol. 2015, 50, 1166.

5. http://www.unep.org/transport/pcfv/PDF/Session3-AsiaTanDagang-MEPChina.pdf, accessed in December 2015.

6. Gao, S.; Chen, X.; Abro, R.; Abdeltawab, A. A.; Al-Deyab, S. S.; Yu, G.; Ind. Eng. Chem. Res. 2015, 54, 9421.

7. Hernández-Maldonado, A. J.; Yang, R. T.; Ind. Eng. Chem. Res. 2003, 42, 123.

8. Hernández-Maldonado, A. J.; Yang, F. H.; Qi, G.; Yang R. T.; Appl. Catal., B 2005, 56, 111.

9. Baeza, P.; Aguila, G.; Gracia, F.; Araya, P.; Catal. Commun. 2008, 9, 751.

10. Jiang, W.; Zhu, W.; Li, H.; Wang, X.; Yin, S.; Chang, Y.; Li, H.; Fuel 2015, 140, 590.

11. Jiang, W.; Zhu, W.; Chang, Y.; Chao, Y.; Yin, S.; Liu, H.; Zhu, F.; Li, H.; Chem. Eng. J. 2014, 250, 48.

12. Ko, N. H.; Lee, J. S.; Huh, E. S.; Lee, H.; Jung, K. D.; Kim, H. S.; Cheong, M.; Energy Fuels 2008, 22, 1687.

13. Zhu, W.; Dai, B.; Wu, P.; Chao, Y.; Xiong, J.; Xun, S.; Li, H.; Li, H.; ACS Sustainable Chem. Eng. 2015, 3, 186.

14. Zhu, W.; Wang, C.; Li, H.; Wu, P.; Xun, S.; Jiang, W.; Chen, Z.; Zhao, Z.; Li, H.; Green Chem. 2015, 17, 2464.

15. Shan, G.; Xing, J.; Zhang, H.; Liu, H.; Appl. Environ. Microbiol. 2005, 71, 4497.

16. Monticello, D. J.; Curr. Opin. Biotechnol. 2000, 11, 540.

17. Alessandro, N.; Tonucci, L.; Bonetti, M.; Deo, M. D.; Bressan, M.; Morvillo, A.; New J. Chem. 2003, 27, 989.

18. Liu, S. Z.; Wang, B. H.; Cui, B. C.; Sun, L. L.; Fuel 2008, 87, 422.

19. Schmitz, C.; Datsevitch, L.; Jess. A.; Chem. Eng. Sci. 2004, 59 , 2821.

20. Zannikos, F.; Lois, E.; Stournas. S.; Fuel Process. Technol. 1995, $42,35$.

21. Otsuki, S.; Nonaka, T.; Takashima, N.; Qian, W. H.; Ishihara, A.; Imai, T.; Kabe, T.; Energy Fuels 2000, 14, 1232.

22. Ramírez-Verduzco, L. F.; Torres-García, E.; Gómez-Quintana, R.; González-Peña, V.; Murrieta-Guevara, F.; Catal. Today 2004, 98, 289.

23. Campos-Martin, J. M.; Capel-Sanchez, M. C.; Perez-Presas, P.; Fierro, J. L. G.; J. Chem. Technol. Biotechnol. 2010, 85, 879.

24. Sobati, M. A.; Dehkordi, A. M.; Shrahokhi, M.; Fuel Process. Technol. 2010, 91, 1386.

25. Shiraishi, Y.; Tachibana, K.; Hirai, T.; Komasawa, I.; Ind. Eng. Chem. Res. 2002, 41, 4362.

26. Aquino, A. S.; Bernard, F. L.; Vieira, M. O.; Borges, J. V.; Rojas, M. F.; Vecchia, F. D.; Ligabue, R. A.; Seferin, M.; Menezes, S.; Einloft, S.; J. Braz. Chem. Soc. 2014, 25, 2251.

27. Zhang, M.; Li, M.; Chen, Q.; Zhu, W.; Li, H.; Yin, S.; Li, Y.; Li, H.; RSC Adv. 2015, 93, 76048.

28. de Souza, M. O.; J. Braz. Chem. Soc. 2014, 25, 2140.

29. Zhang, S. G.; Zhang, Z. C.; Green Chem. 2002, 4, 376.

30. Zhang, S. G.; Zhang, Q. L.; Zhang, Z. C.; Ind. Eng. Chem. Res. 2004, 43,614 .
31. 10. Alonso, L.; Arce, A.; Francisco, M.; Soto, A.; J. Chem. Thermodyn. 2008, 40, 966.

32. Chu, X. M.; Hu, Y. F.; Li, J. G.; Liang, Q. Q.; Liu, Y. S.; Zhang, X. M.; Peng, X. M.; Yue, W. J.; Chin. J. Chem. Eng. 2008, 16, 881.

33. Eßer, J.; Wasserscheid, P.; Jess, A.; Green Chem. 2004, 6, 316.

34. Bösmann, L.; Datsevich, A.; Jess, A.; Lauter, C.; Schmitz, P.; Wasserscheid, P.; Chem. Commun. 2001, 23, 2494.

35. Huang, C. P.; Chen, B. H.; Zhang, J.; Liu, Z. C.; Li, Y. X.; Energy Fuels 2004, 18, 1862.

36. Yu, G.; Li, X.; Liu, X. X.; Asumana, C.; Chen, X.; Ind. Eng. Chem. Res. 2011, 50, 2236.

37. Asumana, C.; Yu, G.; Li, X.; Zhao, J. J.; Liu, G.; Chen, X.; Green Chem. 2010, 12, 2030.

38. Devi Wilfred, C.; Salleh, M. Z. M.; Mutalib, M. I. B.; Sep. Sci. Technol. 2015, 50, 159.

39. Ali, S. H.; Hamad, D. M.; Albusairi, B. H.; Fahim, M. A.; Energy Fuels 2009, 23, 5986.

40. Xu, D.; Zhu, W. S.; Li, H. M.; Zhang, J. T.; Zou, F.; Shi, H.; Yan, Y. S.; Energy Fuels 2009, 23, 5929.

41. Li, H. M.; Jiang, X.; Zhu, W. S.; Lu, J. D.; Shu, H. M.; Yan, Y. S.; Ind. Eng. Chem. Res. 2009, 48, 9034.

42. Zhu, W. S.; Li, H. M.; Jiang, X.; Yan, Y. S.; Lu, J. D.; Xia, J. X.; Energy Fuels 2007, 21, 2514.

43. Lo, W. H.; Yang, H. Y.; Wei, G. T.; Green Chem. 2003, 5, 639.

44. Li, F. T.; Kou, C. G.; Sun, Z. M.; Hao, Y. J.; Liu, R. H.; Zhao, D. S.; J. Hazard. Mater. 2012, 205, 164.

45. Chen, X. C.; Song, D. D.; Asumana, C.; Yu, G. R.; J. Mol. Catal. A: Chem. 2012, 359, 8.

46. Lu, L.; Cheng, S. F.; Gao, J. B.; Gao, G. H.; He, M. Y.; Energy Fuels 2007, 21, 383.

47. Zhao, D. S.; Sun, Z. M.; Li, F. T.; Shan, H. D.; J. Fuel Chem. Technol. 2009, 37, 194.

48. Gao, H. S.; Guo, C.; Xing, J. M.; Zhao, J. M.; Liu, H. Z.; Green Chem. 2010, 12, 1220.

49. Yu, G.; Zhao, J.; Song, D.; Asumana, C.; Zhang, X.; Chen, X.; Ind. Eng. Chem. Res. 2011, 50, 11690.

50. Nie, Y.; Dong, Y. X.; Bai, L.; Dong, H. F.; Zhang, X. P.; Fuel 2013, 103, 997.

51. Zhao, D. S.; Wang, Y. N.; Duan, E. H.; Molecules 2009, 14, 4351.

52. Chen, X.; Guo, H.; Abdeltawab, A. A.; Guan, Y.; Al-Deyab, S. S.; Yu, G.; Yu, L.; Energy Fuels 2015, 29, 2998.

53. Zhang, C.; Pan, X. Y.; Yu, M. J.; Jin, L.; Wu, G.; Chem. Eng. J. 2012, 209, 464.

54. Tajik, H.; Niknam, K.; Parsa. F.; J. Iran. Chem. Soc. 2009, 6, 159.

55. Wang, W.; Shao, L.; Cheng, W.; Yang, J.; He, M.; Catal. Commun. 2008, 9, 337.

Submitted: August 12, 2015 Published online: December 16, 2015 